Dossiê

\title{
Ciências Sociais Computacionais: um novo paradigma para as Ciências Sociais?
}

\author{
Computational Social Science: a new paradigm \\ to Social Sciences?
}

Ciencia Social Computacionales: ¿un nuevo paradigma para las Ciencias Sociales?

\section{Organizadores}

\section{Patrícia P. Pavesi}

DataKula Lab/Universidade Federal do Espírito Santo, Brasil.

E-mail: pavesi.patricia@gmail.com

\section{Julio Valentim}

DataKula Lab/Universidade Federal do Espírito Santo e Urbanot, Brasil.

E-mail: juliovalentim2020@gmail.com

A banalização de tecnologias e a sua incorporação e corporificação em nossa vida cotidiana (Hine, 2020) criou volumes sem precedentes de dados sobre nossos comportamentos em sociedade. Esse "Big Data" abriu novas oportunidades estimulantes para cientistas sociais trabalharem em direção a uma compreensão quantitativa, qualitativa e computacional de sistemas sociais complexos.

Neste cenário, surge uma nova disciplina conhecida como Ciências Sociais Computacionais (CSC), um campo de investigação multidisciplinar do universo social em várias escalas, desde atores individuais até os maiores agrupamentos. 
A CSC tem se caracterizado como um novo campo da ciência que não se limita a Big Data e à análise de redes sociais ou modelos de simulação social, mas compreende tudo isso, bem como outras áreas da investigação científica, como Ciência da Computação, Engenharia da Computação, Estatística e Ciência de Dados Sociais. A CSC tem por objetivo processar dados e executar simulações em escala planetária, levando em consideração toda a população mundial. Principalmente, porque eventos que ocorrem em um lugar podem ter enormes consequências no outro lado do mundo.

Em um mundo de crises financeiras, ciclos de protestos cada vez mais frequentes, pandemias, canais de comunicação inteiramente novos e padrões inéditos de comportamento, a CSC surge de uma clara urgência por uma maior compreensão da complexidade de nossa sociedade global interconectada e da capacidade de aplicar os conhecimentos globais e locais gerados por ela nas decisões políticas.

Desde o advento das tecnologias computacionais na primeira metade do século XX e da computação eletrônica na década de 1970, tais ferramentas vêm sendo incorporadas aos processos de pesquisa no âmbito das Ciências Sociais. A incorporação de novos recursos e objetos técnicos na pesquisa acadêmica, por sua vez, sempre suscita reflexões acerca do peso e do impacto do avanço tecnológico, em termos de ampliação das lentes e precisão dos instrumentos de pesquisa - e sua qualificação como divisores de águas na Ciência. Neste sentido, os pioneiros das CSC costumam estabelecer a analogia entre o impacto que a descoberta do microscópio representou para as Ciências Naturais e o impacto que o advento das tecnologias digitais e recursos computacionais exerce no tocante à reavaliação de repertórios teóricometodológicos e nas próprias matrizes curriculares (Oliveira, 1995; Barnes, 1982) nas disciplinas do espectro das Humanidades, especialmente nas Ciências Sociais.

O surgimento da Ciência Social Computacional abre vários questionamentos e intensifica o movimento autorreflexivo que as Ciências Sociais vivenciam desde as chamadas "Virada Linguística" e "Ontológica" iniciadas na segunda metade do Século XX. Desse surgimento, emergem diferentes questões e angústias epistemológicas. Entre elas:

- Esse enfoque preponderante em métodos quantitativos e experimentais nas Ciências Sociais não seria um retrocesso do campo e a retomada de um paradigma científico positivista?

- As CSC são uma nova ciência ou uma amplificação, através do uso de ferramentas computacionais, dos métodos e teorias já consolidados pelas Ciências Sociais? 
- As Ciências Sociais correm o risco de se tornarem obsoletas se não adotarem os poderes computacionais de coleta, manipulação, análise, visualização e predição baseadas em dados oferecidos pela CSC?

A composição deste Dossiê foi pautada nessas questões epistêmicas e em outras circundantes, procurando dar uma resposta ao desafio de se indicar novas maneiras de se pensar propositiva e criticamente as pesquisas de Ciências Sociais Computacionais, em termos empíricos e teóricos. Além disso, o Dossiê procura também contribuir tanto para a abertura desse novo campo de estudos na área das Ciências Sociais no Brasil, quanto para promover todos os benefícios que pesquisas oriundas dele possam oferecer.

\title{
As Ciências Sociais Computacionais
}

Da fundação da Social Science Computer Review em $1983^{1}$, passando pela publicação, em 2012, do Manifesto de Ciência Social Computacional ${ }^{2}$, estudiosos de diferentes disciplinas vêm empreendendo esforços no sentido de caracterizar o campo e seus propósitos e fundamentos teórico-metodológicos. No próprio Manifesto, Conte et al. (2012:20), reconhecendo as origens diversas em várias disciplinas, definem a CSC como:

\begin{abstract}
[...] um novo tipo de investigação da sociedade habilitado pelas TIC, uma abordagem verdadeiramente interdisciplinar, onde cientistas sociais e comportamentais, cientistas cognitivos, teóricos de agentes, cientistas da computação, matemáticos e físicos cooperam lado a lado para chegar a modelos inovadores e teóricos dos fenômenos alvo. Os cientistas sociais da computação acreditam fortemente que uma nova era começou na compreensão da estrutura e função de nossa sociedade em diferentes níveis. Por um lado, a ciência social computacional visa favorecer e tirar proveito de dados massivos de TIC. Por outro lado, é uma ciência baseada em modelos, que produz modelos preditivos e explicativos. Portanto, pretende-se lucrar com os instrumentos de modelagem disponibilizados pelas TIC para a produção de modelos generativos de sistemas multiagentes em grande escala. Ambos os objetivos devem ser alcançados para transformar as ciências sociais em ferramentas aplicáveis que podem informar os tomadores de decisão sobre questões de grande preocupação.
\end{abstract}

As Ciências Sociais Computacionais também são apresentadas por Edelmann et al. (2020:04) “como um campo interdisciplinar que avança na proposição de teorias acerca do comportamento humano, aplicando técnicas computacionais a grandes conjuntos de dados de sites de mídia social, a Internet ou outros arquivos digitalizados, como registros

\footnotetext{
${ }^{1}$ A Social Science Computer Review "foi o primeiro periódico de caráter interdisciplinar com o objetivo específico de analisar e disseminar estudos sobre os usos metodológicos da computação em Ciências Sociais (Sociologia, Antropologia, Ciência Política, Economia, Psicologia) e os impactos da informática na sociedade". Esta citação foi extraída de um dos artigos deste Dossiê escrito por Cláudia Siqueira Baltar e Ronaldo Baltar.

${ }^{2}$ A primeira versão em língua inglesa foi publicada em 2012 no número 214 da revista The European Physical Journal-Special Topics.
} 
administrativos". ${ }^{3}$ Já Lazer et al. $(2020: 1061)^{4}$, por sua vez, as definem como “o desenvolvimento e a aplicação de métodos computacionais a dados comportamentais humanos complexos, geralmente em grande escala (às vezes simulados)".

Ainda que possam existir particularidades na definição do que sejam as CSC nos trabalhos de diferentes pesquisadores, há um relativo consenso entre eles no que diz respeito à concepção de vida social com a qual trabalham, e que está ancorada nas noções de "emergência" e "complexidade". Do mesmo modo, há um certo consenso quanto à abordagem metodológica que passa pela incorporação de métodos e ferramentas computacionais e aproveitamento de Big Data $^{5}$ que permitem a criação de diferentes formas de compreensão da dinâmica social de pequenos e grandes grupos de pessoas de forma ética.

As investigações em labs de CSC se dão em três níveis de aplicação: 1) Fase Empírica: construção de Big Data (Bancos de Dados Públicos e/ou de Silos Comerciais, Dados coletados em Campo, por meios automatizados, semi-automatizados e artesanais) e Web Scraping e limpeza de dados; 2) Fase Analítica: análise de Redes Sociais, construção de modelos por Machine Learning e Processamento de Linguagem Natural para categorizar dados e formular hipóteses; e 3) Fase Teórica: transformação do modelo de Machine Learning em uma Simulação Computacional Baseada em Agentes para fazer experimentos, previsões, predições e formular teorias.

Desde as suas origens nos anos de 1980, o novo campo já vem sendo consolidado, com penetração em diferentes países. Um levantamento acerca da produção científica envolvendo os termos "ciências sociais computacionais" (em língua inglesa) feito por Edelmann et al. (2020), mostra que houve um aumento considerável no número de artigos em diferentes campos desde 2012. Neste estudo, os autores também identificaram as disciplinas nas quais essa agenda de pesquisa é mais ativa, a saber, Gestão e Negócios, Psicologia e Educação ${ }^{6}$. No que toca às

\footnotetext{
${ }^{3}$ Na proposição desta definição, os autores deixam claro que - dada a multiplicidade de ênfases na compreensão das CSC que emerge da diversidade de disciplinas que podem abarcar - falam a partir da teoria sociológica "porque acreditamos que o futuro do campo dentro da sociologia não depende apenas de novas fontes de dados e métodos, mas também de sua capacidade de produzir novas teorias do comportamento humano ou elaborar explicações existentes do mundo social." (Edelmann et al. 2020:05).

${ }^{4}$ Uma das práticas propostas pelas CSC, dada a sua natureza multidisciplinar, são publicações feitas a muitas mãos. Um dos maiores desafios dos pesquisadores do campo para a divulgação dos resultados de suas pesquisas são justamente os limites e convenções para a publicação de textos em periódicos científicos - especialmente nas Humanidades - em decorrência da limitação na quantidade de autores que as revistas estabelecem (geralmente, de dois a três).

${ }^{5}$ Para as CSC, o Big Data pode ser composto a partir de diferentes fontes por meio de coleta automatizada (por ex., os dados comportamentais gerados em transações online), semi-automatizada (aplicação de surveys à distância apoiada em distribuição por meios digitais) e até mesmo artesanal (por ex., o conteúdo de cadernos de campo utilizados em pesquisa etnográfica com observação participante). Do mesmo modo, pode ser armazenado tanto em silos não integrados à Web, quanto em plataformas digitais e nuvens.

${ }^{6}$ Edelmann (et al. 2020) realizaram uma análise multifacetada - combinando informações de um grande banco de dados bibliométrico, dados de conferências populares na área e vários estágios de codificação humana - para
} 
Ciências Sociais, mesmo com um ritmo mais lento, observa-se que "na Sociologia [...] tem havido um aumento exponencial no trabalho dos sociólogos desde 2010 também" (Edelman et al., 2020:04).

Se por um lado a questão sobre as CSC representarem ou não um novo paradigma para as Ciências Sociais é um pouco mais difícil de responder, por outro lado, são possíveis de serem identificados muitos modos de contribuição que elas podem trazer para a pesquisa social. Dentre essas contribuições, destacam-se: a) a articulação entre escalas de movimentação social com cruzamento de dados e identificação de aproximações e distanciamentos entre ordens globais e locais que não podem ser percebidas a olhos nus; b) avanços na produção de análises assentadas em "dados encontrados" que permitem a percepção e o rastreamento de mudanças de comportamento coletivo e individual em tempo real, ultrapassando limites de diagnósticos baseados em dados históricos; c) avanços na própria compreensão das dinâmicas da vida em ambientes online, das múltiplas interações entre as "três inteligências" - Inteligência Cultural, Inteligência Natural e Inteligência Artificial (Castro, 2020) -, os impactos da modulação computacional de agências, a emergência de novos referenciais éticos, estéticos e dietéticos e novas formas de organização social; d) exploração de recursos computacionais de simulação e imersão para a projeção de futuros por meio da proposição de soluções criativas e éticas para antigos e novos problemas; e) avanços na própria Teoria Social, a partir do uso de novos tipos de dados e métodos para revisitar velhas questões sociológicas que até uma década atrás eram consideradas como parte da ordem numenica ${ }^{7}$;) realização de experimentos pautados em princípios éticos rigorosos que permitem a prospecção de comportamentos com base em desafios que contribuem para a compreensão de processos decisórios como eleições, situações conflituosas e condições de sobrevivência limitadas.

\section{Ciências Sociais Computacionais no Brasil}

No Brasil, apesar de existirem pesquisadores em diferentes regiões envolvidos em investigações alinhadas aos princípios teórico-metodológicos das CSC, elas se apresentam como

identificar todos os artigos de sociólogos que atendem à definição de Ciência Social Computacional. "Nossa estratégia de amostragem foi iniciada com a pesquisa por todas as menções aos termos 'ciência social computacional' ou 'big data' (um neologismo que foi usado nos primeiros dias do campo) no título, resumo ou palavras-chave de artigos designados como parte do campo das Ciências Sociais pelo banco de dados. [...] desenvolvemos um gráfico de série temporal no qual descrevemos o número de publicações em cinco disciplinas acadêmicas em que foi encontrado os termos ciências sociais computacionais ou big data entre 2000 e 2016 . Esse gráfico deve ser tomado como uma medida aproximada da área, dado que artigos individuais não foram revisados por programadores humanos para confirmar que eles estão no assunto de ciências sociais computacionais (Edelmann et al., 2020:07).

${ }^{7}$ O Númeno, na filosofia de Kant, corresponde ao real tal como existe em si mesmo, de forma independente da representação subjetiva. É do reino do "incognoscível”. 
um campo relativamente novo, constando como linha de pesquisa em poucos laboratórios de pesquisa.

No que toca à exploração das possibilidades do novo campo de pesquisa, na primeira década dos anos 2000, Baltar e Siqueira Baltar foram os pioneiros. Eles organizaram o Dossiê Análises Quantitativas e Indicadores Sociais (v. 18. n. 1) da Revista Mediações ${ }^{8}$, o que é um marco importante na trajetória de estudos em CSC no Brasil. Neste número foi publicado o Manifesto da Ciência Social Computacional, texto seminal cuja versão original foi escrita a várias mãos em língua inglesa, em 2012, e traduzido para o português por Ronaldo Baltar, em 2013.

Outro marco importante para as CSC no Brasil foi a realização, em junho de 2021, da primeira edição do Summer Institutes in Computational Social Science (SICSS), evento internacional que reúne todos os anos pesquisadores do campo em diferentes países concomitantemente, cuja edição local foi coordenada pelos pesquisadores Amaro Grassi e Tiago Ventura, com o apoio da FGV/RJ.

Atualmente, dentre os polos de estudos envolvendo CSC ativos no Brasil estão o Projeto Independente Deep Social Labs, o Data Kula Lab (vinculado ao PGCS/UFES), o Laboratório de Humanidades Digitais (LABHDUFBA) e o Programa de Formação Complementar de Ensino de Métodos Digitais (INFOSOC/UEL). Além destas iniciativas, existem ainda pesquisadores independentes que vêm explorando os recursos computacionais em suas pesquisas, o que não necessariamente significa que estejam fazendo pesquisa em CSC, uma vez que ela não se resume ao uso de certas ferramentas. A abordagem das CSC é muito mais complexa e não pode ser reduzida à adoção de métodos computacionais. Ela pressupõe a formulação de perguntas orientadas por princípios analíticos e empiria genuína, o desenvolvimento de estruturas semânticas orientadas por teorias sociais e aprendizado de máquina pautado na exploração de diferentes fontes e métodos de coleta, tendo em vista a garantia e a promoção da diversidade de dados.

Neste sentido, o presente Dossiê, que é a primeira publicação no Brasil exclusivamente composta por artigos voltados para o campo das CSC - seja por meio de exercícios de pesquisa orientados por seus princípios, seja pela avaliação crítica em termos empíricos e teóricos pretende ser uma fonte de informações criteriosas para a ampliação do conhecimento sobre a nova área de estudos no país, bem como, estimular a proposição de novas pesquisas envolvendo métodos e recursos computacionais, sobretudo entre os cientistas sociais.

\footnotetext{
${ }^{8}$ A Revista Mediações é uma publicação quadrimestral do Departamento e do Programa de Pós-Graduação em Sociologia da Universidade Estadual de Londrina (UEL).
} 


\section{Desafios}

Embora as CSC sejam um campo de estudos promissor, ainda despertam uma série de desconfianças por uma parte considerável da comunidade acadêmica, com destaque para sociólogos, antropólogos, cientistas políticos e comunicólogos. Posicionamento compreensível, se considerarmos a longa tradição de estudos críticos focados nos usos e efeitos negativos que as tecnologias de informação e comunicação podem receber e gerar. Preocupação que não pode ser ignorada pelos cientistas sociais computacionais, que devem ser criteriosos, éticos e responsáveis na seleção e uso de instrumentos e métodos de coleta e análise de dados em suas pesquisas. Eles não estão isentos da necessidade de avaliação crítica no que toca a aspectos éticos e políticos de suas escolhas metodológicas. Entretanto, não devem ser paralisados por elas. Concomitantemente à crítica, devem ser propostos novos tipos de práticas que rompam com tendências tecnicistas e evitem a retroalimentação de modelagens de pesquisa orientadas por imaginários epistemológicos ingênuos, fundados na crença da possibilidade de pesquisas científicas não posicionadas ideologicamente.

Além das pré-concepções que limitam o florescimento de novas pesquisas, outros desafios devem ser enfrentados para a ampliação e consolidação das CSC, sobretudo no Brasil, no que diz respeito a:

- Infraestruturas materiais de pesquisa não adequadas para o trabalho em equipes multidisciplinares que dificultam a integração entre diferentes laboratórios. Princípios organizacionais e de gestão educacional que tendem a separar e isolar áreas do conhecimento. Estruturas acadêmicas que mantêm pesquisadores das áreas de Ciência da Computação, Ciência da Informação e cientistas sociais alocados em feudos marcados e práticas de endogenia, sem estímulos institucionais para reuni-los. Além de modelos de financiamento de pesquisas que desencorajam a colaboração entre Centros;

- Ausência de infraestruturas de pesquisa computacional nas próprias universidades, no que toca à capacidade de armazenamento de Big Data, que comportem conjuntos de dados sensíveis em grande escala, garantam o livre acesso para pesquisadores, observando, ao mesmo tempo, o cumprimento de requisitos básicos de segurança e privacidade; 
- Construção daquilo que Buyalslaya, Gallo e Camerer (2021) chamam de "linguagem franca", isto é, um léxico compartilhado que deve ser desenvolvido pelos próprios pesquisadores do campo. Que permita a "tradução" das categorias e conceitos que emergem no atravessamento entre as disciplinas na e pela pesquisa multidisciplinar num vocabulário comum. Isso implica esforço em termos de exercício de alteridade, no sentido de evitar a paralisia das equipes, que muitas vezes é decorrente de disputas pela hegemonia do significado. Além de ser requisito fundamental para a inscrição de práticas (Latour, 1990) em ciência, para a demarcação política e garantia de linhas de financiamento;

- Políticas de acesso e compartilhamento de dados que permitam aos pesquisadores a exploração de data centers para além daqueles mantidos por governos e organizações não-governamentais sem fins lucrativos. Uma legislação mais clara e objetiva que estabeleça critérios mínimos de garantia de privacidade e sobretudo limites para o extrativismo de dados para fins mercadológicos, permitiria o estabelecimento de parcerias com empresas privadas, ampliando a escala e variedade de dados disponíveis para a pesquisa acadêmica;

- Avaliação crítica em relação à origem e, sobretudo, em relação à forma como os dados são coletados. Os dados originados em transações em plataformas digitais proprietárias e até mesmo por governos e organizações sem fins lucrativos não são representações literais da realidade. Eles são modulados por critérios de seleção e registro nem sempre ancorados em princípios científicos, o que dá margem para a produção de vieses, correlações espúrias e diagnósticos inconsistentes;

- Não limitar a pesquisa à exploração de dados gerados por plataformas proprietárias. A sociedade acontece no modo onlife (Floridi, 2015), o que implica no reconhecimento de múltiplos domínios espaço-temporais que recebem maior ou menor ênfase nas agências e contextos específicos. O que nos chama a atenção para o fato de que a experiência na condição de usuários de plataformas e serviços online, além de não ser representativa da maior parte da população, pode ser apenas um padrão dentre tantos outros possíveis. As plataformas nem sempre são projetadas para responder a perguntas de pesquisa, os dados de maior relevância podem não ter sido coletados ou podem ser coletados de uma forma que é confundida por outros elementos do sistema (Edelman et al., 2020). Além de que a disponibilidade de amplos acervos de dados não garante diagnósticos mais confiáveis; 
- Restrições no que toca à publicação de resultados de pesquisas feitas a várias mãos. Uma das inovações propostas pelas CSC, dada a sua natureza multidisciplinar, são publicações assinadas por vários autores. Um dos maiores desafios dos pesquisadores do campo para a divulgação dos resultados de suas pesquisas são justamente os limites e convenções para a publicação de textos em periódicos científicos especialmente nas Humanidades - em virtude da limitação na quantidade de autores que as revistas estabelecem (geralmente, de dois a três);

- Limitações no que toca ao desenvolvimento de skills e expertise para manuseio de recursos computacionais são lacunas reais na formação dos cientistas sociais. A compreensão limitada por desconhecimento técnico dos limites e alcances de métodos e recursos computacionais, arquiteturas, design de plataformas, app's, bots e softwares criam as condições ideais para a rejeição à priori das CSC, baseadas na própria incapacidade de reconhecer hipóteses epistemológicas nulas. Obviamente, a ausência de expertise técnica, traduzida no domínio de linguagens de programação e capacidade de desenvolver códigos, não é requisito indispensável para a pesquisa social, muito menos desqualifica o trabalho dos cientistas sociais leigos no uso de tecnologias digitais. Entretanto, o reconhecimento de que existem sérios déficits em termos de informação tecnológica na formação destes pesquisadores é um passo importante para o desenvolvimento de currículos menos canônicos e mais plurais.

Aqui, elencamos os desafios que julgamos mais evidentes no atual estágio da produção em Ciências Sociais Computacionais. Certamente existem outros, conforme os arranjos mais localizados, seja quanto à especificidade das disciplinas que dela participam, seja do contexto cultural e político do qual suas práticas emergem.

\section{Ciências Sociais Computacionais em Ação}

A multidisciplinaridade como ponto de partida para a construção do conhecimento é mais que uma estratégia metodológica, constitui um valor para as CSC. A radicalidade na atualização deste fundamento epistemológico se apresenta como uma das estratégias mais promissoras, no que diz respeito ao enfrentamento tanto de críticas externas, quanto da própria tendência endógena à esterilização das dimensões sociais inerentes às práticas de pesquisa envolvendo tecnologias computacionais. 
Há um elemento subversivo na forma de pensar a ciência nas CSC, no que diz respeito ao reconhecimento do empreendimento de pesquisa como múltiplo e resultado do trabalho feito a diversas mãos. Ainda que o olhar apressado ancorado na "ciência imaginada" da crítica só tenda a visualizar os laboratórios de pesquisa envolvendo cientistas sociais computacionais como um arranjo bizarro orientado por um modelo fordista de produção do conhecimento, chamamos atenção para o potencial de insurgência e renovação que todo chão de fábrica abriga, o que inúmeros trabalhos de pesquisa etnográfica in loco atestam com robusta pesquisa empírica. Não se trata de "dourar a pílula" reafirmando ideários tecnicistas com novos e sofisticados argumentos. Diz respeito ao reconhecimento de que a aposta em laboratórios híbridos, pensados como redes de circulação de elementos heterogêneos humanos e não humanos é indicador de reconhecimento de que práticas científicas são encarnadas, vivas e se dão em um permanente processo de trocas e iterações complexas.

Se os cientistas sociais computacionais forem capazes de explorar todo o potencial do trabalho multidisciplinar e as linhas de fuga que o atravessamento de elementos heterogêneos (como máquinas e homens) poliniza, poderão contribuir não apenas para revisões de modelos epistemológicos, mas sobretudo, para a desestabilização de horizontes ontológicos já estabelecidos. Para tal, precisam compreender suas próprias práticas como expressão do que Latour (1990) chama de ciência em ação - algo que exige tentativas continuadas de identificação nos laboratórios multidisciplinares de pesquisa, tanto de recorrências, como de singularidades nas situações, contextos e práticas locais que permitam pensar nas problemáticas gerais e métodos compartilhados pelos pesquisadores (Teixeira, 2001). Este tipo de engajamento autorreflexivo pode ser estimulado e intensificado a partir da formação e cultivo de redes interinstitucionais de pesquisadores orientadas por um duplo movimento de pesquisa: a compreensão dos múltiplos fenômenos sobre os quais suas investigações se debruçam e a tematização de suas próprias práticas pensando-as como experimentos sociais.

Este é o desafio que propomos aos leitores deste Dossiê: a) exploração dos artigos que o constituem, estando atentos à originalidade do conhecimento dos fenômenos gerado nos processos de pesquisa que serviram de base para a sua escrita; b) o exercício de um tipo de sensibilidade analítica voltada para a identificação e compreensão das formas como as pesquisas foram feitas, a ritualística, a liturgia, os recursos teóricos, maneirismos, idiossincrasias e ferramentas tecnológicas empregadas no processo.

Neste sentido, o artigo de Cláudia Siqueira Baltar e Ronaldo Baltar, intitulado Reflexões sobre os percursos metodológicos em ciência social computacional, oferece elementos para a compreensão dos múltiplos agentes e agências que participam da formação do campo das CSC. 
Por meio de técnicas computacionais, os autores rastreiam práticas de cientistas sociais computacionais materializadas em sua produção acadêmica publicizada por meio de artigos na base WoS. Além da valiosa contribuição que representa o olhar orientado por dados para a produção do campo publicada em língua portuguesa - territorializando e "localizando" a pesquisa historicamente marcada pela anglofonia -, também desmistificam o bordão caricato da crítica vulgar ("positivismo”), nos alertando para as hipóteses críticas nulas que marcam o imaginário sobre a Inteligência Artificial e os recursos computacionais comum entre estudiosos das Humanidades. Embora, pelos limites de um artigo, não tenham feito a exploração de fôlego dos itinerários que podem ser percorridos para a preparação básica em CSC, fornecem pistas interessantes para pesquisas futuras.

Na sequência, Kleberson Toldo Soares, por meio do trocadilho "outsiders-outliers", no artigo Ciência de Dados Sociais: uma visão sociológica das Humanidades Digitais, nos convida a pensar sociologicamente "o novo petróleo" (os "dados"), bem como as infraestruturas técnicas, recursos computacionais e estatísticos que os modelam. Apoiado na noção de Outsider de Goffman e entendendo os outliers como agentes imbricados em processos de construção de modelos, destaca seu potencial como indicadores de deficiências nos desenhos de pesquisa e/ou em relação à qualidade dos dados que tendem a ser estigmatizados, o que constitui um desperdício metodológico das inúmeras possibilidades que os "desvios" podem conter, sobretudo quando se tratam de "dados sociais". Mesmo considerando as controvérsias, tanto do ponto de vista dos cientistas da computação, quanto dos cientistas sociais em relação à chamada "Ciência de Dados Sociais" - no que toca ao rigor de suas análises, bem como sua orientação pragmática e mercadológica - ele propõe reflexões sobre a ética na confecção e utilização de produtos gráficos que orientam processos de decisão. Sustenta ainda que o refinamento teórico-metodológico a partir de aproximações aos debates do campo das Humanidades Digitais e das CSC pode representar ganhos em termos de legitimidade e rigor para a Ciência de Dados Sociais.

Em A case study on the usage of social network analysis to complement participant observation on Twitter, Vlad Schüler-Costa remonta às origens antropológicas da terminologia e da metodologia de análise de redes sociais. Por meio de revisão bibliográfica de fôlego, desconstrói a linha de argumentação que separa de forma maniqueísta pesquisa etnográfica e pesquisa "quantitativa". A partir de resultados de investigação em etnografia digital conduzida entre 2013 e 2015 no serviço da rede social Twitter, desenvolve uma discussão teóricometodológica sobre o uso de mineração de dados e visualização de redes como complemento "quantitativo" à abordagem "qualitativa" da observação participante. Em uma abordagem característica da Antropologia Digital, se vale tanto de recursos e ferramentas de coleta 
automatizada de dados, quanto de procedimentos de pesquisa artesanais para rastreio online da comunidade "anitwitter". Embora não separe de forma irreconciliável a observação participante e os métodos computacionais, nem minimize o valor das ferramentas computacionais, sua análise sugere - ainda que indiretamente - que seguir a linha dos chamados "métodos mistos" abre possibilidades interessantes de "calibragem" dos recursos da caixa de ferramentas do antropólogo.

O artigo abre uma série de frentes de discussão acerca da incorporação de thick data coletados por meio de observação participante, etnobiografias, etnografia patchwork, etnografia vídeo-reflexiva (Collier; Wyer, 2016; Hor et al., 2014; Carroll et al., 2008), etnografia multimodal (Dicks et al., 2006), etnografia visual (Pink, 2007), história oral e método indiciário no processo de treino, validação e teste para a construção de modelos em Machine Learning. Os elementos analíticos oferecidos pelo autor nos permitem desmontar crenças acerca da anulação ou negação da pesquisa artesanal pelas CSC e seu suposto fetiche por métodos e recursos computacionais.

A abertura da caixa-preta metodológica com o compartilhamento de códigos, algoritmos e outras técnicas de pesquisa por meio de plataformas como GitHub permitem a replicação de técnicas e procedimentos metodológicos que outros pesquisadores utilizaram em seus trabalhos em investigações anteriores com as devidas adaptações para o exame de novos contextos e conjuntos de dados. Esta é uma possibilidade muito explorada nas CSC e é a estratégia de Maria Rita Pereira Xavier e Alexsandro Galeno Araújo Dantas, em Dispositivo de vigilância algorítmica: algoritmos rastreadores e coleta de dados. Neste artigo, os autores problematizam as lógicas algorítmicas e suas armadilhas, analisando o uso de algoritmos rastreadores através de smartphones como uma forma corporativa/empresarial de vigilância por meio de práticas de tracking. A técnica de pesquisa empregada consiste no uso de algoritmos contra vigilantes desenvolvidos por pesquisadores, como Karaj et al. (2019) e Macbeth et al. (2016). Foram pesquisados algoritmos rastreadores em aplicativos e sites, além de identificadas diferentes técnicas pelas quais se dá o rastreio de dados pelos 4 sites mais acessados do Brasil, segundo o ranking Alexa.

Com o olhar voltado para o que acontece "embaixo do capô" dos smartphones - sistema de viva-voz/microfone, acelerômetro e outros sensores - com aporte em Foucault, os autores estabelecem aproximações entre dispositivo (objeto técnico) e Dispositivo (categoria analítica) e celular (objeto técnico) e Celular (técnica disciplinar). Este trabalho chama a atenção para o quanto as hard skills computacionais permitem não apenas uma melhor compreensão do 
funcionamento técnico das infraestruturas tecnológicas, mas, sobretudo, lançam bases para análises teóricas mais sofisticadas e críticas melhor fundamentadas.

Se na primeira década do século XXI a internet foi elemento central na articulação de protestos e reivindicações de grupos à esquerda do espectro político, a segunda década é marcada pela consolidação e ascensão das narrativas da extrema direita e Alt-right (Nagle, 2017). Nesta leitura o universo gamer se apresenta como um dos domínios mais férteis para a arregimentação e articulação de agentes conservadores. Entretanto, Francisco Weichsler, Kerche Nunes e Miguel Mendes em Caminhos cruzados: uma possível radicalização do YouTube Gamer, ao observarem as formas pelas quais os canais do YouTube de direita se apresentam em recomendações algorítmicas sobre jogos, criando conteúdos acessíveis ao público ouvinte como um todo, descobrem que usuários de todos os tipos têm relações comunicativas com seus algoritmos, tanto para serem melhor recomendados, quanto para terem melhores recomendações. O que desconstrói a hipótese que circula na discussão pública e acadêmica sobre o tema que indicava de forma especulativa que os processos algorítmicos de recomendação de conteúdo por design preparam ideologicamente uma geração de homens jovens brasileiros para a radicalização política à direita, principalmente partindo de círculos ligados a jogos eletrônicos (Lewis, 2018; O’Callaghan et al., 2015). Na elaboração de formas de testar esta hipótese, os autores descobriram que a ocupação de espaços digitais pela direita não era tão efetiva a ponto de tornarse incontornável nos caminhos de recomendação algorítmica da plataforma. O que nos chama a atenção para: 1) as ricas possibilidades abertas pelos processos de modelagem computacional de pesquisas, não apenas para uma coleta de dados mais eficiente, mas também para a própria análise teórica, à medida que exigem a reformulação das perguntas; 2) a proatividade dos usuários em relação a operação dos algoritmos, claramente atestada pela conclusão dos autores, orientada por dados, de que a radicalização política manifesta nas plataformas digitais é acima de tudo social e deve ser pensada como um fenômeno sociotécnico.

A exploração de Big Data por meio de métodos computacionais favorece em muitos aspectos as pesquisas longitudinais. Tirando proveito disso, Otávio Vinhas em Os sentidos da Facada em Jair Bolsonaro: uma Análise Sociocibernética de Redes Sociais no Twitter descreve longitudinalmente, a partir de três lapsos temporais, como ocorreram modificações de significados acerca da facada em Jair Bolsonaro no Twitter. Alicerçado em uma lente teóricoepistemológica vinculada à sociocibernética (Almanaguer-Kalixto; Giglietto, 2019) e na compreensão da comunicação com base nos conceitos de complexidade e de auto-organização, conforme desenvolvimentos suscitados pela Teoria dos Sistemas de Niklas Luhmann (1995; 2000; 2006), o artigo descreve a dinâmica de construção de significados no Twitter em torno do 
evento da "facada", no então candidato à presidência do Brasil, Jair Bolsonaro. Por meio de uma metodologia de Análise Sociocibernética de Redes Sociais, combinando métodos computacionais de Análise de Redes Sociais com a abordagem teórico-epistemológica construtivista, voltada à comunicação na sociedade como uma operação complexa, o autor observa como ao longo do tempo as diferentes perspectivas produzidas inicialmente sobre o evento sintetizaram-se em uma polarização política guiada por valores. A pesquisa em perspectiva longitudinal desenvolvida por Vinhas ilustra de forma clara o diferencial que os recursos computacionais oferecem tanto em termos de compreensão da emergência e da complexidade social e aproveitamento de dados históricos e "dados encontrados", quanto do crescimento recente da CSC para além de prerrogativas meramente analíticas, mas também de acessibilidade, reprodutibilidade e transparência na pesquisa social, ampliando e/ou reconfigurando teorias já consolidadas nas Ciências Sociais para um paradigma computacional.

No artigo intitulado Webscraping em R: uma abordagem para investigação em ciências socias, Quemuel Baruque de Freitas Rodrigues, Mayres Lane Pequeno Dos Santos Silva, Marina Félix De Melo e Amurabi Oliveira, atualizam três marcadores importantes no campo das CSC: 1) a preconização do livre acesso aos códigos e práticas de compartilhamento de técnicas de pesquisa; 2) o trabalho em equipe e a política atribuição equitativa da autoria na publicização de resultados de pesquisa; 3) a função didático-pedagógica das publicações científicas associada à produção e apresentação de conhecimento acionável. Por meio da apresentação de uma breve introdução ao uso de algoritmos para coleta de dados em repositórios online sobre investigações no campo das Ciências Sociais, a partir de um modelo empírico de pesquisa sobre produção acadêmica de bolsistas de produtividade do CNPq no Brasil, os autores sumarizam um passo-apasso para o planejamento de algoritmo de scrapping a partir do software R. Ainda que o estudo de caso tenha servido como suporte empírico para a ilustrar a aplicação de técnicas computacionais em pesquisa acadêmica, contribui para o questionamento de um imaginário de crítica social baseado em especulações não orientadas por dados em relação a assimetrias e desigualdade de oportunidades no que toca à produtividade acadêmica no Brasil, seja do ponto de vista regional (proeminência e privilégios das regiões Sudeste e Sul), seja em relação à representatividade em termos de gênero (proeminência da performance dos homens e invisibilização das performances de mulheres). Obviamente, os resultados podem e devem ser questionados, e os autores oferecem subsídios que permitem ao leitor a contestação, inclusive por meio de experimentações hand-on.

Por fim, ainda que existam muitos pesquisadores no Brasil, tanto das Ciências Sociais quanto de outros campos do conhecimento utilizando métodos e recursos computacionais, como 
destacamos anteriormente, isso não é suficiente para qualificar seus trabalhos como práticas em CSC. E muito ainda precisa ser feito para que novas gerações de pesquisadores estejam habilitadas para investigações genuinamente orientadas pelas CSC e não se restrinjam a improvisar adaptações pontuais por meio de citações em trabalhos que envolvem tecnologias computacionais. Visando contribuir avanços neste sentido, este Dossiê Temático oferece tanto elementos para uma compreensão mais panorâmica das questões epistemológicas e teóricometodológicas enfrentadas pelo campo, como das possibilidades de abordagem abertas pelas CSC operacionalizadas nas pesquisas que serviram de base para os artigos que aqui apresentamos.

Boa leitura!

Patricia Pavesi e Julio Valentim

\section{Referências}

ALMANAGUER-KALIXTO, Patricia. E.; GIGLIETTO, Fabio (2019), "Steering the world from where we are: An introduction to the sociocybernetics perspective". Current Sociology, v. 67, n. 4, pp. 47994 [Consult. 18-09-2021]. Disponível em https://doi.org/10.1177/0011392119837573

BALTAR, Ronaldo; BALTAR, Cláudia Siqueira (2013), As Ciências Sociais na Era do Zettabyte. Mediações-Revista de Ciências Sociais, v. 18, n. 1, pp. 11-9.

BARNES, Barry (1982), T-S-Kuhn and Social Science. Macmillan International Higher Education.

BUYALSKAYA, A.nastasia; GALLO, M.arcos; CAMERER, C.olin F (2021), "The golden age of social science". Proceedings of the National Academy of Sciences, v. 118, n. 5.

CASTRO, Eduardo V. (2020), As três Inteligências. Academia.edu [Consult. 20-10-21]. Disponível em http://www.academia.edu/12297791/Open_Access_Meets_Discoverability_Citations_to_Articles_ Posted_to_Academia.edu

COLLIER, A; WYER, M. (2015), "Researching Reflexively with Patients and Families: Two Studies Using Video-Reflexive Ethnography to Collaborate With Patients and Families in Patient Safety Research". Qualitative Health Research, v. 26, n. 7, pp. 979-93.

CONTE, R. et al. (2012), "Manifesto of Computational Social Science". The European Physical Journal Special Topics, 2012, v. 214, n. 1, pp. 325-46 [Consult. 24-10-21]. Disponível em https://doi.org/doi:10.1140/epjst/e2012-01697-8

DICKS, B. et al. (2006), "Multimodal Ethnography”. Qualitative Research, v. 6, n. 1, pp. 77-96.

EDELMANN, A.chim et al (2020), "Computational Social Science and Sociology". Annual Review of Sociology, v. 46, pp. 61-81. 
FLORIDI, Luciano (ed.) (2015), "The Onlife Manifesto: being human in a hypeconnected era". Springer Cham [Consult. 21-10-21] Disponível em https://doi.org/10.1007/978-3-319-04093-6

GÜNEL, Gökçe; VARMA, Saiba; WATANABE, Chika (2020), “A Manifesto for Patchwork Ethnography". Society for Cultural Anthropology, v. 9.

HINE, Christine (2020), Ethnography for the internet: Embedded, embodied and everyday. Routledge.

HOR, S.-Y. et al (2014), "Creating Spaces in Intensive Care for Safe Communication: a video-reflexive ethnographic study". BMJ Quality \& Safety, v. 23, n. 12, pp. 1007-13.

KARAJ, Arjaldo.; MACBETH, Sam; BERSIN, Rémi; PUJOL, Josep M. (2018), WhoTracks.Me: Shedding light on the opaque world of online tracking. Cornell University, Nova York [Consult. 0511-21]. Disponível em https://arxiv.org/abs/1804.08959

LATOUR, Bruno (1990), La science en action. Paris, Pandore.

LAZER, David M. J. et al. (2020), “Computational Social Science: Obstacles and opportunities”. Science, v. 369, n. 6507, pp. 1060-62 [Consult. 20-11-2021]. Disponível em https://doi.org/doi:10.1126/science.aaz8170

LEWIS, Rebecca (2018), Alternative Influence. New York [Consult. 20-10-21]. Disponível em https://datasociety.net/wp-content/uploads/2018/09/DS_Alternative_Influence.pdf

LUHMANN, Niklas (1995), Social Systems: Writing Science. Stanford, Stanford University Press.

LUHMANN, Niklas (2020), The Reality of the Mass Media. Stanford, Stanford University Press.

LUHMANN, Niklas (2006), La sociedad de la sociedad. México, Universidad Iberoamericana.

MACBETH, Sam.; MODI, Kornak; PUJOL, Josep M.; ZHONGHAO, Yu. Tracking the trackers (2016), in, Proceedings of the $25^{\text {th }}$ International Conference on World Wide Web - WWW 2016. Montreal, Canada, pp. 121-32.

NAGLE, Angela (2017), Kill All Normies: Online Culture Wars from 4chan and Tumblr to Trump and The Alt-Right. Londres, Zero Books.

O'CALLAGHAN, Derek et al. (2015), "Down the (white) rabbit hole: The extreme right and online recommender systems". Social Science Computer Review, v. 33, n. 4, pp. 459-78, Publisher: Sage Publications Sage CA, Los Angeles, CA.

OLIVEIRA, Roberto Cardoso de (1995), “Antropologia e a Crise dos Modelos Explicativos”. Estudos Avançados, v. 9, pp. 213-28.

PINK, Sarah (2007), Doing Visual Ethnography. London, Sage Publications.

TEIXEIRA, Márcia de Oliveira (2001), A ciência em ação: seguindo Bruno Latour. História, Ciências, Saúde-Manguinhos, v. 8, n. 1, pp. 265-72. 